Goldschmidt 2021 Abstract

https://doi.org/10.7185/gold2021.5063
[2] Allard et al. (2018), Chem. Geol. 479, $136-150$

[3] Allard et al. (2020), Pal. Pal. Pal 554, 109918

\title{
Record of Cenozoic weathering episodes in central Amazon basin
}

\author{
CLAIRE ANSART, PHD $^{1}$, DJAMILA DEMRI ${ }^{1}$, THIERRY \\ ALLARD $^{2}$, DAMIEN CALMELS ${ }^{1}$, CÉCILE E $^{2}$ \\ GAUTHERON $^{1}$, DAMIEN GUINOISEAU ${ }^{3}$, PIERRE \\ AGRINIER $^{4}$, CÉCILE QUANTIN ${ }^{1}$ AND ADRIANA HORBE ${ }^{5}$ \\ ${ }^{1}$ GEOPS, Université Paris-Saclay, CNRS \\ ${ }^{2}$ Sorbonne Université, Université Pierre et Marie Curie, IMPMC, \\ UMR CNRS 7590 \\ ${ }^{3}$ Université de Paris, Institut de Physique du Globe de Paris, \\ CNRS \\ ${ }^{4}$ Université de Paris, Institut de Physique du Globe de Paris, \\ CNRS UMR 7154 \\ ${ }^{5}$ Instituto de Geociências, Universidad de Brasilia \\ Presenting Author: claire.ansart@universite-paris-saclay.fr
}

Laterites are deep regoliths known to form under warm and humid conditions over long period of time. However, reconstructing the precise timing of laterite development (i.e. number and duration of weathering episodes) and prevailing climate conditions remains challenging. During weathering, secondary minerals, such as kaolinite, hematite or goethite form and can potentially provide key information on past climate conditions.

The Amazon basin is of particular interest because it has remained in equatorial position since the Cretaceous, experiencing a favorable climate for the development of laterite. Consequently, $80 \%$ of the Amazon basin is covered by laterites. However, large-scale geodynamic events (e.g. Andean uplift and the closure of Panama isthmus), may have modified the regional climate during the Cenozoic, leading to rejuvenation or destabilization/erosion of lateritic formations. Previous studies have explored the Cenozoic weathering history of central Amazonia [1] [2] [3]. Using (U-Th)/He dating on ferruginous pisoliths and Electronic Paramagnetic Resonance dating of kaolinite, several weathering episodes have been evidenced: $>25$ Ma, 14-11 Ma, 9-6 Ma and Quaternary.

Here, we focus on a lateritic profile from the central Amazon basin (100 km north of Manaus, Brazil), which has been developed on the Cretaceous Alter do Chão Formation. To understand the functioning and to specify the timing of formation of this profile, mineralogical and geochemical investigations and dating of Fe-(oxyhydr-)oxides were performed. Kaolinites, dominant within the profile (except for the duricrust and pisolitic units), show a progressive evolution from large and well-ordered structures at the base, to badly ordered structures in the ferralsol. This confirms the transformation of an initial generation. The presence of a hematite-rich duricrust may indicate a tropical climate with pronounced dry seasons, while the presence of both pisolitic level and gibbsite in the ferralsol suggests an episode of duricrust dismantlement under relatively wet conditions. New $\mathrm{Fe}$-(oxyhydr-)oxides dating for that region will be thoroughly discussed in terms of sequence and timing of the profile formation together with paleoclimatic forcing.

[1] Balan et al. (2005), GCA 69, 2193 - 2204 